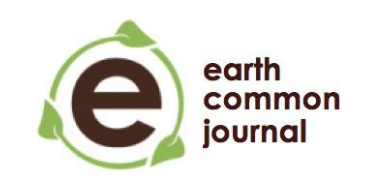

Earth Common Journal

Changing Climates: Social, Political, Economic

MacEwan University

Volume 6, Number 1, October 2016

\title{
Article
}

\section{Species Conservation in a Globalized World}

Sharlene Engel, MacEwan University, Canada*

\begin{abstract}
In today's globalized world, international cooperation and information sharing becomes increasingly important. This paper examines the criteria provided in the United State's Endangered Species Act, the European Union's Habitat Directive, and the International Union for Conservation of Nature's Red List. The interplay between these lists creates barriers to conserving and protecting global biological diversity, resulting in a need for more international cooperation and collaboration.
\end{abstract}




\section{Introduction}

We live in a globalized world where international cooperation and information sharing is often required. This need for connection is prevalent when it comes to species conservation. Different national and international organizations and policies exist with the aim of conserving biological diversity around the world. However, the manner in which these groups define criteria for endangered and threatened species varies. As these categories are often the basis for conservation action and extinction prevention measures, it becomes important to ensure these categories are consistent.

The different criteria provided by the United States of America's Endangered Species Act (ESA), the European Union's Habitat Directive (HD), and the International Union for the Conservation of Nature's (IUCN) Red List, combined with pre-existing limitations, could cause a discrepancy in information and conservation on a global scale. The differences in categorization, the lack of information, consistency, and poor communication across national and international lists pose a threat to the legislation's success in conserving global biological diversity.

\section{Endangered Species Act}

"The fundamental purpose of the US Endangered Species Act (ESA)," Wolf, Hartl, Carroll, Neel, and Greenwald (2015) say, "is not only to prevent extinction, but also to recover species to the point that they are no longer threatened or endangered" (p. 200). The ESA (1973) defines endangered species as "any species which is in danger of extinction throughout all or a significant portion of its range", while a species is understood to be "any species which is likely to become an endangered species within the foreseeable future throughout all or a significant portion of its range" (3.6; 3.19). As Wolf et al. (2015) explain, a recovered species is "one that is no longer endangered or threatened" (p. 201). The ESA provides strict criteria on how an endangered or threatened species can be reclassified as recovered.

Wolf et al. (2015) summarize the ESA recovery criteria: ecosystem conservation, threat reduction, and low extinction risk over an appropriate range (p. 201). To be considered a recovered species, the species' ecosystem must be conserved and of sufficient quality, threats to the species must have been reduced, and the species must have strong numbers over a range of habitat (p. 201). Soulé, Estes, Miller, and Honnold (2005) and Estes, Tinker, and Bodkin (2010) establish that ecosystem conservation is important not only to ascertain the ecosystem's size, quality, and connectivity, but also to ensure the species can return to its niche (as cited in Wolf et al., 2015). Without a stable 
ecosystem, a species cannot be considered recovered. Wolf et al. (2015) stress this importance: "If ecological function is not considered, a species could be declared recovered even while remaining functionally extinct” (p. 202). The danger of an unstable ecosystem could prevent a species from fully recovering by not allowing sustainable growth.

Similarly, the ESA (1973) establishes five threat factors that must be controlled or extinguished for recovery: loss of habitat or range, exploitation, disease, poor protective regulations, and any other threat factors (3.9). These risks must be contained such that the species can continue to survive without ESA conservation. As Neel, Leidner, Haines, Goble, and Scott (2012) explain, this strategy can be so effective that, "for a few species, removing threats alone might reduce their extinction risk to levels sufficient for delisting" (p. 656). Mace et al. (2008) warns that monitoring threats to species is crucial, as these threats can change irregularly and erratically with human population growth and development (p. 1429).

Finally, the species must have a large enough population across a sufficient range to continue to prosper. No definition of significant portion or range is provided in the legislation. If an endangered and threatened species is "at risk throughout all or a significant portion of their range", Vucetich Nelson, and Phillips (2006) and Carroll, Vucetich, Nelson, Rohlf, and Phillips (2010) argue a recovered species must therefore be secure throughout all or a significant portion of its range (ESA, 1973, 3.6; p. 201; p. 201). As Neel et al. (2012) point out, "demographic measures are the most basic quantities necessary for understanding population trajectories and the probabilities of persistence " (p. 656). Their research revealed a lower extinction risk with a higher population (p. 655). To ensure continued survival, a species must be sufficiently present throughout its habitat, such that a weak population does not die out.

\section{Habitat Directive}

The Habitat Directive, specifically Article 17, "obliges the EU member states to report the conservation status of the habitats and species listed in annexes of that directive every six years following an agreed, standardized methodology" (Moser et al, 2016, p. 1). Evans and Romaõ (2014) outline the criteria required for any species to be considered at a favourable, unfavourable-inadequate, or unfavourable conservation status in the HD. A favourable conservation status meets the following criteria:

- numbers are stable (in both growth and decline) throughout its range 
- growing and not smaller than the "preferred reference range"

- population must be higher than or equal to "favourable reference population"

- normal reproduction, mortality, and age structure

- habitat of adequate size and either stable or increasing in size

- habitat quality is satisfactory for the species' continued survival

- $\quad$ species' threats and pressures are not meaningful

- $\quad$ species has long-term viability (p. 21)

By contrast, an unfavourable-bad conservation status is defined as follows:

- range loss of more than $1 \%$ annually within a specified time frame or below the "favourable reference range" by greater than $10 \%$

- population loss of more than $1 \%$ annually within a specified time frame or below the "favourable reference population" by greater than $25 \%$ or reproduction, mortality, and age structures vastly different from normal

- size of the habitat is too small or the quality is too poor to allow for long-term survival

- threats and pressures to the species are strong, resulting in a poor prospect for its future (p. 21)

An unfavourable-inadequate species has any other combination of the factors of range, population, habitat, and longevity (p. 21). These classifications are similar to the concerns shown in the recovery criteria in the ESA, with consideration extended to range, population size, and threat reduction. Furthermore, these parameters include quantitative measures for issuing an unfavourable-bad conservation status. As described by the Joint Nature Conservation Committee (2014), the HD mandates that EU member states "maintain or restore European protected habitats and species listed in the annexes at a favourable conservation status” (para. 5).

Cardoso (2012) explains that annexes detailed in the HD are the "basis for the protected species lists" (p. 169). The European Commission (2016) provides an explanation of protections granted to the three annexes included in the HD: annex II 
species have "core areas of their habitat...designated as sites of community importance (para 6). These sites must be managed in accordance with the ecological needs of the species" (para. 6). For annex IV species, which also include numerous annex II species, the HD mandates, "a strict protection regime must be applied across their entire natural range within the EU" (para. 7). Finally, for annex V species, "member states must ensure their exploitation and taking [hunting] in the wild is compatible with maintaining them in a favourable conservation status" (para. 8). Through the annexes, species can gain the support they need to maintain or work towards a positive conservation status.

The question remains on how species are assigned an annex. The European Commission (2007) explains:

Annex II was chosen for species for which the conservation of their (often quite specific) habitat is the principal factor determining their survival and well-being. The protection and management of sites were selected here as the appropriate instrument, which includes not only the maintenance of species habitats, but also, where appropriate, their restoration. The group of species listed in Annex IV may be less suited to conservation by establishing protected areas, but instead needs "physical" protection of the actual species, as well as protection of the most important parts of their habitat (i.e. their breeding sites and resting places) throughout the territory of a member state. This is because of the specific threats

they face, the measures needed to counteract them, the species' pattern of occurrence (i.e. scattered), or the type or specific character of their habitat. For the third group of species listed in Annex V, which may be exploited by human beings, this exploitation must be managed — if necessary — in order to ensure a favourable conservation status. (p. 14)

The annexes identify threats towards a species and assign a correlating protective measure. Compared to the ESA, where a species is considered only to be threatened, endangered, or recovered, a species can belong to multiple HD annexes simultaneously. As the European Commission (2007) explains, this duality can arise when species "are subject to a combination of threats and should consequently be the target of a range of measures" (p. 14). Following this system, the HD can offer different levels of protection to species in accordance with that species' needs.

\section{Red List}

According to the ICUN (2015), 29\% of the 77,340 species on the Red List are threatened, and the number of species facing immediate extinction is rising (as cited in 
Moser et al., 2016). As Mace et al. (2008) state, "The IUCN Red List categories are intended to reflect the likelihood of a species going extinct under prevailing circumstances" (p. 1428). There are three categories for species: critically endangered, endangered, and vulnerable. These categories are stairs, in that a species that is critically endangered (the highest stair), is also both endangered and vulnerable (the second and first stairs). These categories are differentiated by risk of extinction over time and by a further five criteria: high decline rate (criteria A), small range and decline (criteria B), small population size and decline (criteria C), very small population size (criteria D), and unfavourable quantitative analysis (criteria E). Criteria A accounts for the rate of change between past and present (or predicted future) populations over time with consideration to threats, while criteria $\mathrm{B}$ considers the species with respect to its geographical range or risks to its habitat. In criteria $C$, a population is small and declining, whereas in criteria $D$, a population is small and at risk due to internal processes. Finally, criteria E opens the possibility for assessors to use a quantitative analysis to measure risk of extinction ( $p$. 1430-1436). These five criteria encompass the same factors considered in the ESA and HD.

As Cooke (2008) says, this system "requires assessors to indicate the threats that triggered a listing of the taxon concerned at the finest level possible" (p. 172). Additionally, "species assessments are compiled from published and unpublished information and typically include expert input by one or more 'assessors"' (Rodrigues, Pilgrim, Lamereux, Hoffmann, \& Brooks, 2006, p. 71). The assessments are peer reviewed by at least two 'evaluators' assigned by the relevant 'Red List Authority' (Rodrigues, Pilgrim, Lamereux, Hoffmann, \& Brooks, 2006, p. 71). Through this process, the ICUN includes many checks and authorities before assigning a category to a species.

\section{Global Conservation}

The ESA, HD, and IUCN Red Lists discuss the topic of biological diversity differently, but with the common goal of conservation. As shown above, the three pieces of legislation have their own unique terminology, criteria, and categories. As Schnittler and Günther (1999) and Grigera and Ubeda (2002) note, a lack of consistent wording between lists often results in terms having different meanings nationally and globally (as cited in Brito et al., 2010, p. 1155). Miller et al. (2007) add that differences in listing procedures between countries constrict the ability to compile information from the lists (as cited in Brito et al., 2010, p. 1155). The lack of consistent terminology and classification standards is a large barrier for communication and knowledge sharing between national and international lists. While many of the underlying principles and 
goals are shared, these differences, compounded with common barriers, can cause discrepancies and biological conservation as a whole to suffer as a result.

\section{Uncertainty and Lack of Information}

Neel et al. (2012) examined the transition and possibly of transition of threatened and endangered species listed on the ESA to a recovered status: since December 2009, 25 species have been delisted (p. 652). As the researchers explain:

Around $90 \%$ of the species with potential for delisting have quantitative recovery objectives, the quantification of species decline is limited, because $46 \%-71 \%$ of these species lack population data, and 67\%-98\% lack individual abundance data either historically, at listing, or when the recovery plan was written. (p. 654)

One of the biggest barriers to accurately categorizing species is a lack of information about them. Some of this information is hard to find as it remains unpublished or difficult to access (as cited in Washington et al., 2014, p. 482). This information gap is nothing new, nor is it isolated to the ESA. Cardoso (2012) confirms that species on the ICUN Red List were "chosen according to the existing knowledge at the time, when data on many taxa and countries were largely unavailable" (p. 170). As more information is added to data, it then becomes imperative to reconcile the data with the lists and examine any potential changes to species classification or status that might consequently occur. Rodrigues et al. (2006) make special note that the Red List differentiates changes that are "a result of genuine improvement or deterioration in status from those as a result of improved knowledge (i.e. of population sizes) or taxonomy (i.e. newly split species)" (p. 75). Increasing the base of information about species allows more accurate decisions and assessments to be made, and it is important to be aware of how such changes occur.

\section{National and Global Communication and Consistency}

Brito et al. (2010) examined national red lists of Brazil, China, Colombia, and the Philippines against the IUCN Red List. They found 64\% of species had the same classification. Despite the consistency, China's Red List had a 25\% correspondence rate with the classifications of the ICUN's Red List. There was an average of $14 \%$ of species that were listed as threatened globally, but not nationally. An average of only $2 \%$ of species were documented as threatened nationally, but assessed as not threatened by the IUCN. This latter discrepancy can represent the risk of extinction experienced by a smaller subpopulation rather than the whole species population. Other explanations 
include when the species is thought to populate a nation by global agencies, but not national ones (or the other way around), when species within the nation have a higher risk of extinction than the global population, or when a population within a nation is stable despite prevalent unstable populations globally (p. 1156). Their research shows a need for stronger communication between national and international organizations to identify gaps in information and strengthen the knowledge base. Rodríguez et al. (2000) also examined the connection between local lists and the ICUN Red List. Their results too revealed a need for stronger collaboration: "National assessments tend to incorporate data from global assessments, but the reverse is much less frequent. This decreases the efficiency of conservation at the national level, where actions are most likely to have an impact" ( $p$. 241). This finding shows a need for global lists to work with national lists to gather and compile information.

There are ways in which the discrepancies between national and international lists can in themselves provide new information. Washington et al. (2014) explains such differences can "provide insights into country-level or taxonomic patterns in deviations from the hierarchy, which may be useful for conservation planning" (p. 488). These differences can also help to fill information gaps in lists.

Brito et al. (2010) remind us of the potential consequences of a continued lack of information sharing: "Erroneous exclusion of species as threatened on either global or national level could lead to extinction" (p. 1155). Without proper species classifications and conservation status, a species is not guaranteed the protection it requires for continued survival. Missing information or a failure to communicate findings can thus have an irreversible effect on species. The need for more consistency and improved communication between national and international bodies is also echoed in the findings and observations of Brito et al. (2010), Rodrigues et al. (2006), and Washington et al. (2014).

\section{Conclusion}

The ESA, HD, and Red List all classify and categorize species according to different, yet related, criteria. These differences can prohibit the accuracy and ease of sharing information between national and international lists, creating barriers that prohibit accurate species status assessment and limiting the information base. This is not to say the future is bleak for biological conservation. As Collar (1996) reminds us, the ICUN Red Lists collect, synthesize, and disseminate information that would elsewise be left inaccessible (as cited in Rodrigues et al., 2006, p. 72). Article 17 of the HD requires member states to communicate their evaluations of conservation status using a 
standardized methodology, which shows awareness for a consistent format between national and international bodies (Moser et al., 2016, p. 1). Sharing information and imposing a consistent system throughout different national and international lists becomes integral to maintaining up-to-date and relevant lists and for global biological conservation as a whole.

* Author: Sharlene Engel is entering her fourth year of MacEwan Bachelor of Communication Studies this fall. "Species Conservation in a Globalized World" represents her interest in international cooperation and improving global diversity, which stems from a love of words and the natural world.

\section{References}

Brito, D., Ambal, R. G., Brooks, T., Silva, N. D., Foster, M., Hao, W. ...Rodríguex, J. V. (2010). How similar are national red lists and the IUCN Red List? Biological Conservation, 143, 1154-1158. doi:10.1016/j.biocon.2010.02.015

Brooks, T. M., Wright, J., Sheil, D. (2009). Evaluating the success of conservation actions in safeguarding tropical forest biodiversity. Conservation Biology, 23, 1448-1457. doi.org/10.1111/j.1523-1739.2009.01334.x

Cardoso, P. (2012). Habitats Directive species list: Urgent need of revision. Insect Conservation and Diveristy, 5, 169-174. doi: 10.1111/j.1752-4598.2011.00140.x

Carroll, C., Vucetich, J.A., Nelson, M.P., Rohlf, D. J., \& Phillips, M. K. (2010). Geography and recovery under the U.S. Endangered Species Act. Conservation Biology, 24, 395-403. doi:10.1111/j.1523-1739.2009.01435.x

Cooke, S. J. (2008). Biotelemetry and biologging in endangered species research and animal conservation: Relevance to regional, national, and IUCN Red List threat assessments. Endangered Species Research, 4, 165-185. doi: 10.3354/esr00063

Endangered Species Act, 16 U.S.C. \1532 (1973).

Estes, J. A., Tinker, M. T., \& Bodkin, J. L. (2010). Using ecological function to develop recovery criteria for depleted species: Sea otters and kelp forests in the Aleutian 
Archipelago. Conservation Biology, 24, 852-860. doi:10.1111/j.15231739.2009.01428.x

European Commission. (2007). Guidance document on the strict protection of animal species of Community interest under the Habitats Directive 92/43/EEC. Retrieved from http://ec.europa.eu/environment/nature/conservation/species/guidance/pdf/ guidance_en.pdf

European Commission. (2016, June 10). The Habitats Directive. Retrieved from http://ec.europa.eu/environment/nature/legislation/habitatsdirective/index_en. htm

Evans, D., Romão, C. (2014). Article 17 reporting - assessments of conservation status at the EU biogeographical level — public consultation. ETC/BD Technical Paper 3/2014. ETC/BD, Paris.

Grigera, D., Ubeda, C. (2002). Una revisión de los trabajos sobre categorizaciones y prioridades de conservación de los vertebrados de Argentina. Ecología Austral 12, $163-174$.

IUCN. (2015). Threatened species in past and present IUCN Red Lists. Retrieved from http://www.iucnredlist.org/about/summary-statistics\#Tables_1_2

Joint Nature Conservation Committee. (2014, October). Council Directive 92/43/EEC on the Conservation of natural habitats and of wild fauna and flora. Retrieved from http://jncc.defra.gov.uk/page-1374

Mace, M. G., Collar, J. N., Gaston, K. J., Hilton-Taylor, C., Akçakaya, H. R., LeaderWilliams, N., ... Stuart, S. N. (2008). Quantification of extinction risk: IUCN's system for classifying threatened species. Conservation Biology, 22, 1424-1442. doi: 10.1111/j.1523-1739.2008.01044.x

Miller, R.M., Rodríguez, J.P., Aniskowicz-Fowler, T., Bambaradeniya, C., Boles, R., Eaton, M.A., Gärdenfors, U., Keller, V., Molur, S., Walker, S., Pollock, C. (2007). National threatened species listing base on IUCN criteria and regional guidelines: 
current status and future perspectives. Conservation Biology 21, 684-696. doi:10.1111/j.1523-1739.2007.00656.x

Moser, D., Ellmauer, T., Evans, D., Zulka, K. P., Adam, M., Dullinger, S., \& Essl, F. (2016). Weak agreement between the species conservation status assessments of the European Habitats Directive and Red Lists. Biological Conservation, 198, 1-8. http://dx.doi.org/10.1016/j.biocon.2016.03.024

Neel, M. C., Leidner, A. K., Haines, A., Goblw, D. D., \& Scott. J. M. (2012). By the numbers: How is recovery defined by the US Endangered Species Act? BioScience, 62, 646-657. doi: 10.1525/bio.20U.62.7.7

Rodrigues, A. S. L., Pilgrim, J. D., Lamoreux, J. F., Hoffmann, M., \& Brooks, T. M. (2006). The value of the IUCN Red List for conservation. TRENDS in Ecology and Evolution, 21, 71-76. http://dx.doi.org/10.1016/j.tree.2005.10.010

Rodríguez, J. P., Ashenfelter, G., Rojas-Suárez, Fernández, J. J. G., Suárez, L., and Dobson, A. P. (2000). Local data are vital to worldwide conservation. Nature, 403, 241. doi:10.1038/35002183

Schnittler, M. \& Günther, K. F. (1999). Central European vascular plants requiring priority conservation measures: an analysis from national red lists and distribution maps. Biodiversity and Conservation, 8, 891-925.

Soulé, M. E., Estes, J. A., Miller, B., \& Honnold, D. L. (2005). Strongly interacting species: Conservation policy, management, and ethics. BioScience, 55, 168-176.

Vucetich, J. A., Nelson, M.P., \& Phillips, M. K. (2006). The normative dimension and legal meaning of endangered and recovery in the U.S. Endangered Species Act. Conservation Biology, 20, 1383-1390. doi:10.1111/j.1523-1739.2006.00493.x

Washington, H., Baillie, J., Waterman, C., \& Milner-Gulland, E. J. (2014). A framework for evaluating the effectiveness of conservation attention at the species level. Oryx, 49, 481-491. doi:10.1017/S0030605314000763 
Wolf, S. Hartl, B. Carroll, C., Neel, M. C., \& Greenwald, D. N. (2015). Beyond PVA: Why Recovery under the Endangered Species Act is more than Population Viability. BioScience, 65, 200-207. doi:10.1093/biosci/biu218 